\section{Список литературы:}

1. Федеральный государственный образовательный стандарт среднего общего образования. Утвержден Приказом Министерства образования и науки Российской Федерации от 17.05.2012 г. № 413 // Российская газета. №5812 (139). 21.06.2012.

2. Философский словарь / под ред. И.Т. Фролова. М.: Политиздат, 1980. 445 с.

3. Педагогика: учебное пособие / В.А. Сластенин, И.Ф. Исаев, А.И. Мищенко, Е.П. Шиянов. М.: Школа-Пресс, 1998. 512 с.

4. Педагогика физической культуры / под ред. С.Д. Неверковича. М.: Физкультура и спорт, 2006. 528 с.

5. Педагогика: учебное пособие / В.Г. Рындак, Н.В. Алехина, И.В. Власюк и др. / под ред. В.Г. Рындак. М.: Высшая школа, 2006. 495 с.

6. Коджаспирова Г.М., Коджаспиров А.Ю. Словарь по педагогике. М.: ИКЦ «МарТ»; Ростов-наДону: Издательский центр «МарТ», 2005. 448 с.

7. Основы управления подготовкой юных спортсменов / под ред. М.Я. Набатниковой. М.: Физкультура и спорт, 1982. $280 \mathrm{c.}$

8. Терминология спорта. Толковый словарь спортивных терминов / сост. Ф.П. Суслов, Д.А. Тышлер. М.: СпортАкадемПресс, 2001. 480 с.
9. Дуранов М.Е., Чернецкий Ю.М. Общая педагогика. Челябинск: ЮУрГУ, 1999. 186 с.

10. Платонов В.Н. Общая теория подготовки спортсменов в олимпийском спорте. К.: Олимпийская литература, 1997. 583 с.

11. Дуранов М.Е. Профессионально-педагогическая деятельность и исследовательский подход к ней. Челябинск: ЧГАКИ, 2002. 276 с.

12. Загвязинский В.И., Атаханов Р. Методология и методы психолого-педагогического исследования. М.: Академия, 2001. 208 с.

13. Краевский В.В., Бережнова Е.В. Методология педагогики: новый этап. М.: Академия, 2008. 400 с.

14. Сластенин В.А., Каширин В.П. Психология и педагогика. М.: Академия, 2001. 480 с.

15. Матвеев Л.П. Теория и методика физической культуры. М.: Физкультура и спорт, 1991. 543 с.

16. Холодов Ж.К., Кузнецов В.С. Теория и методика физической культуры и спорта. М.: Академия, 2014. $480 \mathrm{c}$.

17. Философский энциклопедический словарь / гл. ред: Л.Ф. Ильичев, П.Н. Федосеев, С.М. Ковалев, В.Г. Панов. М.: Сов. энциклопедия, 1983. 840 с.

\title{
APPLIED BASES OF THE PERSON PHYSICAL CULTURE EDUCATION PROCESS MANAGEMENT
} (C) 2018

Korovin Sergey Semenovich, doctor of pedagogical sciences, professor of Theory and Methodology of Sports, Adaptive Physical Culture and Medico-Biological Foundations of Physical Education Department Orenburg State Pedagogical University (Orenburg, Russian Federation)

Abstract. The quality of school education as a system of the directional usage of the physical culture values is conditionally provided through the effectiveness of the teacher's activities (as well as by all the school's subjects) in realization of the management actions with regards to this system functioning optimization, its integrity and stability in the process of the base aim achievement - students' physical culture education. Meanwhile the management activity itself as a system stipulates, in its turn, for the definite stages of the management work with regards to the fulfillment a corresponding content of the management actions. So, based on the existing notions about the internal school management system as well as on the experience in management the process of physical education in the bringing up a student's physical culture, the following management activities stages and their main content are defined: collection and processing (analysis, synthesis) information about the object of management (physical education); diagnosis of the state of the object (subject) of management and the activity forecast, establishment of the aim (the anticipation of the results in physical culture and sports activities), private goals in the process of students' physical culture teaching, management decision taking (the combination of the mental operations and actions, that define a problematic situation, its transfer to the task, formation of the physical culture and sports activities motives and hypothesis about the means of its decision); planning (foreseeing the way how the physical education process will be developed in time); working out a physical culture and sports activities content (system regulation of the elements and processes, that form the subject or phenomenon; the content of physical culture and sports activities - the system of knowledge, movement abilities and skills, experience of the creative value-oriented activity, that provide for the personality's physical culture formation); activity organization (as a combination of actions for regulation and co-ordination of subject-object physical culture and sports activities in teaching, education and development of the personality); control (complex) of education activity (its biomedicine and psycho-pedagogical forms); collection and processing of education activities results; correction of the aim, planning, content and the processes of physical culture and sports activities and physical education organization.

Keywords: physical education of students; values of physical culture; stages; structure and content of management activities; bringing up subject's physical culture; types of management actions.

\section{ТЕОРЕТИЧЕСКИЕ АСПЕКТЫ ПРОБЛЕМЫ ИНТЕРНАЦИОНАЛИЗАЦИИ ВЫСШЕГО ОБРАЗОВАНИЯ В СОВРЕМЕННОМ МИРЕ}

Кузовенкова Ксения Олеговна, преподаватель кафедры экономики и менеджмента Филиал Самарского государственного технического университета в г. Новокуйбышевске (2. Новокуйбышевск, Самарская область, Российская Федерация)

Аннотация. В данной работе рассматриваются теоретические аспекты понятийного аппарата интернационализации высшего образования с точки зрения отечественных и зарубежных ученых. Автор приходит к 
выводу, что интернационализация высшего образования оценивается специалистами неоднозначно, причем единство мнений не наблюдается ни в оценке преимуществ и возможных рисков, связанных с интернационализацией, ни в терминологическом определении самого этого процесса. Однако в ходе работе автором определяется, что интернационализация образования является одним из факторов становления глобального пространства высшего образования и может быть представлена множеством процессов, в числе которых мобильность студентов и преподавательского состава, гибкость образовательных программ, формирование новых международных образовательных стандартов, включение образовательных стандартов и международного измерения в учебные программы, межвузовское взаимодействие (создание образовательных ассоциаций), - это формы интернационализации образования, без которых немыслимо развитие системы образования любого государства. В статье акцентируются внимание на делении интернационализации на «внутреннюю», подразумевающую формирование такого климата и культуры внутри вуза, которые поддерживают и продвигают межкультурное и международное взаимопонимание, и «внешнюю», т.е. образование за границей, интернациональное образование, представляющее собой процесс обмена образовательными продуктами и услугами между странами с использованием различных образовательных технологий и посредством соглашений на административном уровне. Автором также определены базовые составляющие культуры университета, которые необходимо развивать в условиях интернационализации. На основании исследуемых материалов представлена типология интернационализации, которая рассматривается на внутреннем, внешнем, национальном, трансграничном и международном уровнях.

Ключевые слова: интернационализация; вуз; система высшего образования; интеграция; образовательный процесс; глобализация; модель сотрудничества; компоненты культуры университета; международное сотрудничество; институциональное партнерство; профессиональная мобильность; дистанционное обучение; глобальный рынок.

В настоящее время в России проходят разнообразные и многочисленные глобальные процессы. В их основе лежит тенденция, которая заключается в расширении на фоне глобализации культурных, экономических, политических и других связей Российской Федерации с другими государствами. Благодаря данной тенденции выявляются разнообразные проблемы, а также суть изменений, происходящих на данном этапе развития мирового сообщества.

В изучении проблем высшего образования в международном измерении и глобальном контексте центральной темой и, вероятно, наиболее частотным понятием стала интернационализация. В нашей стране этот термин, первоначально употреблявшийся для описания соответствующих тенденций в экономической, социальной и культурной сферах, получает широкое употребление применительно к профессиональному образованию в конце XX - начале XXI века. Это связано с тем, что «международная деятельность» российских образовательных учреждений получила к тому времени некую переоценку и стала носить более осознанный, целенаправленный и систематический характер.

Интернационализация высшего образования оценивается специалистами неоднозначно, причем единство мнений не наблюдается ни в оценке преимуществ и возможных рисков, связанных с интернационализацией, ни в терминологическом определении самого этого процесса. Многочисленность и разнообразие явлений, которые вобрало в себя понятие интернационализации, привело в итоге к заметной путанице и неясности. «Интернационализация высшего образования, - пишет Р. Яп Чао-мл. - превратилась в довольно широкое понятие, обозначающее целый спектр идей и видов деятельности, которые иногда перекрывают друг друга, а иногда друг другу противоречат» [1, с. 7].

Отсутствие единой дефиниции интернационализации отражает уровень теоретического осмысления данного явления, который многие специалисты считают весьма низким. Специалисты выделяют различные ключевые аспекты интернационализации и пытаются определить данное понятие с рассмотренных позиций.

В академических кругах этот термин был впервые использован более десяти лет назад, когда К. Хан и У. Тейхлер изучили интернационализацию немецкой системы высшего образования. Тематические исследования отражают актуализацию международной деятельности, включенной в общую политику и деятельность в области высшего образования в немецких учреждениях. В их статье были освещены некоторые области, которые, как ожидается, изменятся в ближайшие годы, вызванные потребностями и эволюцией интернационализации: структура учебных программ / степеней, уровни компетенций выпускников, системы экзаменов, общая структура систем высшего образования, управление учреждениями, а также оценки учебных программ. Определение К. Хана подразумевает, что интернационализация больше не является отдельным столпом политики и стратегий университета, а интегрирована во все другие основы: образование, исследования, людские ресурсы, финансы, студенческие дела, факультеты и т. д. [2, c. 124].

Широко распространенное определение от Дж. Найт: «Интернационализация в высшем образовании - это процесс интеграции международного, межкультурного или глобального измерения в цель, функции или предоставление высшего образования» $[3$, с. 9].

У. Тейхлер определяет интернационализацию высшего образования следующим образом: «Исходя из неоднородного множества явлений, интернационализация не просто означает переменную деятельность по пересечению границ на подъеме, а, скорее, существенные изменения: во-первых, из преобладающе «вертикальной» модели сотрудничества и мобильности в сторону доминирования международных отношений на равных условиях; во-вторых, от казуистических действий к систематической политике интернационализации; в-третьих, от отключения конкретных международных мероприятий, с одной стороны, и от другой интернационализации основных 
видов деятельности в направлении комплексной интернационализации высшего образования» [4, с. 232].

В апреле 2015 года Ганс Де Вит (директор Центра по изучению международного высшего образования при Бостонском колледже) в сотрудничестве с Фионой Хантер (заместитель директора Центра интернационализации высшего образования (ЦИВО) Католического университета Святого Сердца в Милане) предложили новое определение интернационализации: «Преднамеренный процесс интеграции международного, межкультурного или глобального измерения в цель, функции и предоставление высшего образования в целях повышения его качества и эффективности для всех учащихся и педагогов и внесения весомого вклада в жизнь общества» [5, с. 43].

Т.Л. Стенина и А.О. Чамчиян, проанализировав основную научную литературу по данной теме, пришли к выводу, что наиболее обширным определением является следующее: «Интернационализация высшего образования - целенаправленный процесс интеграции международного, межкультурного или глобального измерения в задачи, функции и методы обучения в сфере высшего образования с целью улучшения качества образования и исследований для всех участников образовательного процесса, а также внесения значимого общественного вклада» [6, с. 73].

Согласно определению отечественного исследователя А.А. Шумейко, интернационализация образования на разных уровнях (секторальном, национальном и институциональном) представляет собой процесс, при котором цели, функции и организация предоставления образовательных услуг приобретают международное измерение [7, с. 127]. Следует акцентировать внимание на самом определении интернационализации в сфере высшего образования, традиционно включающее в себя в международной практике следующие аспекты:

а) «внутреннюю» интернационализацию, подразумевающую формирование такого климата и культуры в вузе, которые поддерживают и продвигают межкультурное и международное взаимопонимание, в то же время реализация всех проектов, программ и исследований включает в себя международное измерение. К примеру, она ведется в соответствии с международными стандартами, включением зарубежных наработок, а также совместно с зарубежными вузами-партнерами;

б) «внешнюю» интернационализацию, интернациональное образование, представляющее собой процесс обмена образовательными продуктами и услугами между странами с использованием различных образовательных технологий и посредством соглашений на административном уровне [7, с. 128].

По мнению Лоренц В., трансграничное образование явилось результатом глобализации образовательных рейтингов и представляет собой интеграцию систем образования разных стран и развитие международного сотрудничества, а также является показателем модернизации системы образования [8, с. 18].

Изучив научные работы С. Керр, можно выявить, что интернационализация объединяет в себе несколько аспектов - это международные обмены учеными, студентами, преподавателями, а также объединение содержания учебных планов [9, с. 112].

По мнению Р. Скотта, международные факторы высшего образования также выделяют несколько ас- пектов, смежных по своей сути с другими исследованиями: обмены студентами, сотрудничество образовательных и научных учреждений, обмены преподавателями, обмены идеями [10, с. 121].

Опираясь на труды профессора В.М. Курицина, исследовавшего процесс интернационализации в сфере образования, необходимо сказать о том, что академическая и профессиональная мобильность студентов и преподавателей - одно из ключевых звеньев интернационализации европейского высшего образования [11, с. 87].

Глубокое и всестороннее рассмотрение процесса интернационализации содержится в трудах профессора Н.В. Попова и профессора А.И. Сурыгина, которые сходятся во мнении, что интернационализация в сфере высшего образования является одной из важнейших характеристик конкурентоспособности современных университетов, а ее показатели, с учетом этого, обладают большим весом среди иных показателей эффективности вузовской деятельности. Соответственно, интернационализация вуза оказывает влияние на ключевые составляющие качества образования, качества программ, качество выпускника и качество образовательного процесса [12, с. 1047].

Таким образом, можно заметить единство взглядов иностранных и отечественных исследователей, которые выделяют несколько основных аспектов в понятии интернационализации: разработка и внедрение единых программ, программы обмена преподавателями, научными сотрудниками и студентами, а также тесное сотрудничество образовательных учреждений.

Стоит выделить пять составляющих университетской культуры, которые важно развивать в условиях интернационализации образования:

- лидирующая позиция университета в культурной среде;

- взаимодействие преподавателей с коллегами на международном уровне в научно-исследовательском процессе или персональные контакты между ними по всему миру;

- обеспечение доступа иностранных студентов к образовательным программам (в дисциплинарном, финансовом плане и т.д.);

- наличие иностранных профессоров и студентов и их активное участие в жизни университета;

- существование дополнительных услуг, помимо образовательных (оборудованные кампусы, конференц-залы, центры по изучению других культур и языков, студенческие объединения, общественные организации и т.д.) [13, с. 139].

Но даже качественной разработки полноценной стратегии повышения глобальной конкурентоспособности высших учебных заведений в контексте интернационализации недостаточно для насыщения высококвалифицированными кадрами различных сфер национальных экономик. Национальные и региональные интересы требуют повышения роли соответствующей подготовки кадров [14, с. 38].

Для целостного восприятия исследуемой темы считается необходимым конкретизация понятия глобализации, а также изучение типологии интернационализации как внутренней, внешней и национальной, трансграничной, международной. 
Под глобализацией стоит понимать процесс интеграции, в некотором аспекте унификации, в ходе которого определенная область социальной деятельности (в данном случае - образование) приобретает характер единой глобальной системы.

Под внутренней интернационализацией понимается включение межкультурного и межнационального измерений в содержание учебных планов, процессы преподавания и обучения, а также во внеаудиторную работу со студентами $[15$, с. 166$]$.

Что же касается внешней интернационализации, то под ней понимается процесс обмена образовательными продуктами и услугами между странами с использованием различных образовательных технологий и посредством соглашений на административном уровне.

Интернационализация на национальном уровне предполагает наличие соответствующей государственной политики и целевых программ, которые могут включать мероприятия, относящиеся к внешней политике, развитию внешней торговли, мигра- ционных процессов, научно-техническому сотрудничеству и межкультурных коммуникаций $[16$, с. 280].

Интернационализация в контексте трансграничного образования являет собой весь набор образовательных программ, или образовательных услуг, или курсов обучения, в том числе дистанционное образование, во время реализации которых студенты проживают и обучаются за рубежом.

Интернационализация образования в виде международной академической мобильности предполагает перемещение студентов, преподавателей, сотрудников, а также аспирантов на определенный срок в образовательное или научное учреждение другой страны для обучения, ведения преподавательской и исследовательской деятельности, а также для того, чтобы повысить квалификацию, с последующим возвращением в свое учреждение высшего образования и признанием в нем зарубежных результатов обучения или работы.

Касательно типологии интернационализации наиболее наглядным методом для понимания структуры является схема, изображенная на рис. 1.

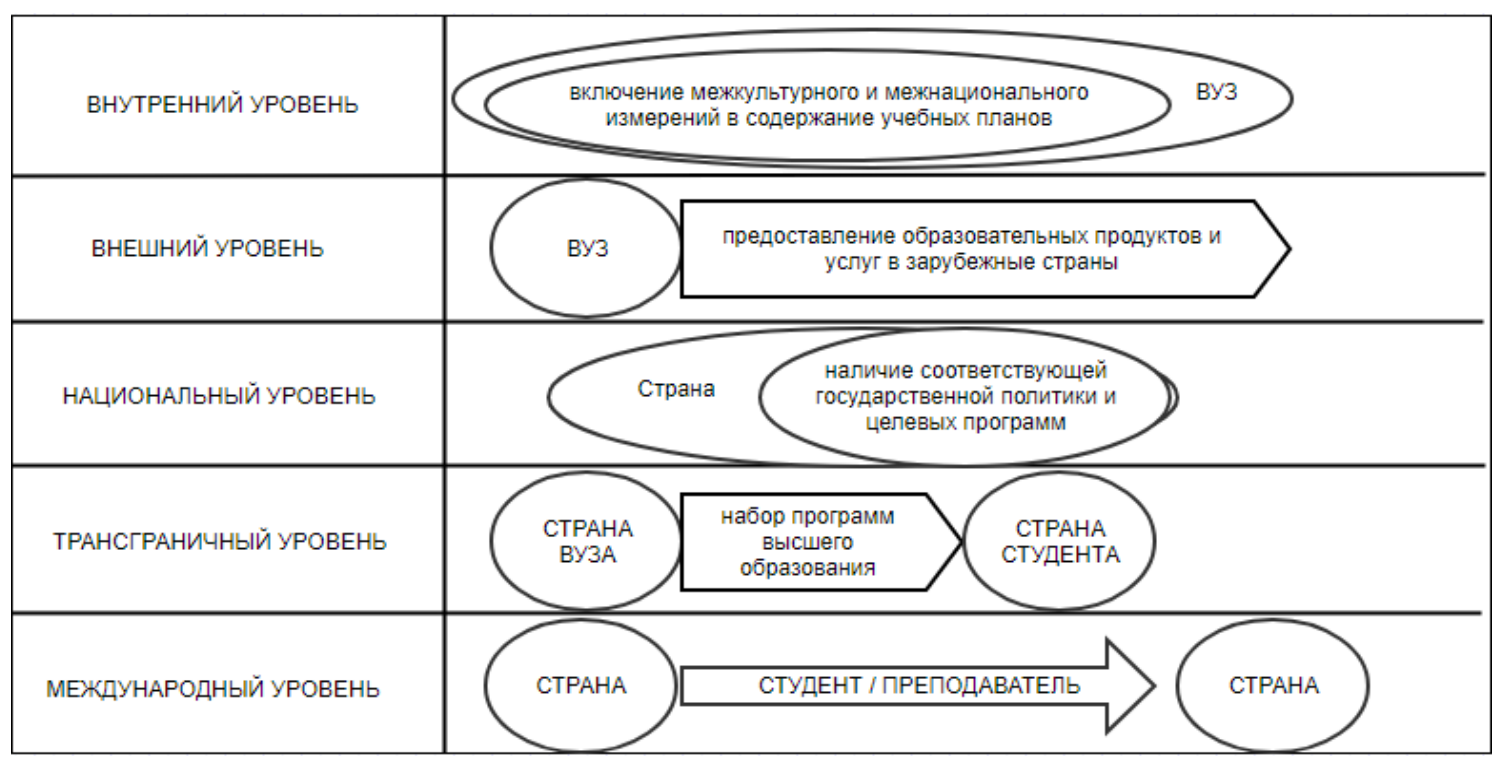

Рисунок 1 - Уровни интернационализации образования

Вышесказанное заставляет полагать, что развитие процессов глобализации и интернационализации экономики и бизнеса поставило перед образованием новую цель - подготовить профессиональные кадры, которые будут способны эффективно работать в изменяющихся условиях глобализации, будут готовы к конкуренции, будут лидировать в будущем.

Активное развитие дистанционного обучения, а также современных информационных технологий позволило размыть национальные границы для доступа к образовательным услугам. Доступность образования наряду с универсальностью полученных знаний являются несомненными преимуществами интернационализации образования. В условиях нового мира без границ и при экспоненциально развивающихся технологиях процесс интернационализации современного образования необратим. Если важна подготовка специалистов, имеющих возможность и необходимость работы в любой точке планеты в национальных и международных компаниях, то сам процесс обучения не может быть осуществлен в узких пределах одного учебного заведения.
Мобильность студентов и преподавательского состава в образовательных целях, гибкость образовательных программ, создание новых международных образовательных стандартов, включение образовательных стандартов и международного измерения в учебные программы, межвузовское взаимодействие (создание образовательных ассоциаций) являются формами интернационализации образования, без которой немыслимо развитие системы образования любого государства.

\section{Список литературы:}

1. Яп Чао-мл. Р. Интернационализация высшего образования в парадигме «идеализм - утилитаризм» // Международное высшее образование. 2015. Зима. № 78. C. 7-9.

2. Hahn K. Die internationalisierung der deutschen hochschulen: Kontext, kernprozesse, konzepte und strategien. Taschenbuch: VS Verlag für Sozialwissenschaften; Auflage: 2004. $408 \mathrm{~s}$.

3. Knight J. Internationalization remodeled: Definition, approaches, and rationales // Journal of Studies in International Education. 2004. Vol. 8 (1). P. 5-31. 
4. Teichler U., Kehm B.M. Research on Internationalisation in Higher Education // Journal of Studies in International Education. 2011. № 1. P. 231-239.

5. De Wit H. Internationalization of higher education in the United States of America and Europe: a historical, comparative, and conceptual analysis. 2002. $270 \mathrm{c}$.

6. Стенина Т.Л., Чамчиян А.О. Анализ содержания понятия «интернационализация высшего образования» в контексте педагогики // Образовательные стандарты и педагогическая практика. 2016. № 2. C. 69-75.

7. Шумейко А.А. Интернационализация и регионализация высшего образования как важный фактор развития конкурентоспособности университета // Современные проблемы науки и образования. 2015. № 6. C. 124-129.

8. Лоренц В. Трансграничное обучение - новые возможности и перспективы. M.: LAP Lambert Academic Publishing, 2014. $60 \mathrm{c}$.

9. Kerr C. Higher Education Cannot Escape History: Issues for the Twenty-First Century. Albany: State University of New York Press. 1994. 248 p.

10. Scott R. Massification, Internationalization and Globalization // The Globalization of Higher Education. Buckingham. Buckingham: Open University Press, 1998. P. 108-129.

\section{THEORETICAL ASPECTS OF HIGHER EDUCATION INTERNATIONALIZATION PROBLEM IN THE MODERN WORLD}

(C) 2018
11. Курицын В.М. Международное сотрудничество и академическая мобильность преподавателей и студентов // Высшее образование в России. 2012. № 10. C. 87-92.

12. Краснощеков В.В. Интернационализация вуза как фактор повышения качества выпускника // Фундаментальные исследования. 2014. № 6. Ч. 5. С. 10451048.

13. Бирюкова Н.А., Красильникова Н.В. Оценка интернационализации высшего образования: опыт европейских стран // Вестник Марийского государственного университета. 2014. № 2 (14). С. 138-142.

14. Катровский А.П., Губа В.П. Высшее образование в России - процесс трансформации и интеграции // Вестник Полесского государственного университета. Серия общественных и гуманитарных наук. 2015. № 2. C. 32-40.

15. Красильникова Н.В. Интернационализация высшего образования в Европе: опыт Болонского университета // Образование и наука. 2015. № 8. С. 163175 .

16. Интернационализация высшего образования: тенденции, стратегии, сценарии будущего / М.Л. Агранович [и др.]. М.: Логос, 2010. 280 с.

\title{
Kuzovenkova Kseniya Olegovna, lecturer of Economics and Management Department Branch of Samara State Technical University in Novokuibyshevsk (Novokuibyshevsk, Samara Region, Russian Federation)
}

\begin{abstract}
This paper discusses conceptual aspects of higher education internationalization problem in terms of native and foreign scientists. The author of the study comes to the conclusion that internationalization of higher education is assessed differently by specialists and there is no consensus in assessing benefits and possible risks associated with the internationalization and in the terminological definition of the process itself. Key components of internationalization methodology in the context of the university are analyzed. In the course of the work the author determines that the internationalization of education is one of the factors in the formation of a global space for higher education and can be represented by a multitude of processes, including international academic mobility, introduction of world standards, internationalization of training courses, intercultural programs, etc. The author defines basic components of the university culture which must be developed in conditions of internationalization. The definitions of the concepts of internal, external, national, cross-border and international levels of the internationalization of higher education are considered.

Keywords: internationalization; university; higher education; integration; educational process; globalization; model of cooperation; components of university culture; international cooperation; institutional partnership; professional mobility; distance learning; global market.
\end{abstract}

\section{ПРОЕКТИРОВАНИЕ УЧЕБНО-МЕТОДИЧЕСКОГО КОМПЛЕКСА ДИСЦИПЛИНЫ «МЕТОДИКА ОБУЧЕНИЯ БИОЛОГИИ» И ЕГО ПРИМЕНЕНИЕ В ПОДГОТОВКЕ БУДУЩИХ УЧИТЕЛЕЙ БИОЛОГИИ}

(C) 2018

Марина Антонина Васильевна, кандидат педагогических наук, доцент кафедры биологии, географии и химии

Арзамасский филиал Национального исследовательского Нижегородского государственного университета им. Н.И. Лобачевского (г. Арзамас, Нижегородская область, Российская Федераџия)

Аннотация. В статье рассматривается вопрос об одном из важнейших условий реализации основной профессиональной образовательной программы направления подготовки 44.03.05 Педагогическое образование (с двумя профилями подготовки) (уровень бакалавриата) - учебно-методическом обеспечении, базовым компонентом которого является учебно-методический комплекс дисциплины. Особое внимание уделяется рассмотрению структуры и содержания учебно-методического комплекса дисциплины «Методика обучения 